Information about the author: Zoia Adamia - PhD, prof., Research worker of Institute of Russian Language and Literature at Tskum-Abkhazian Academy of Sciences. Editor-in-Chef of Scientific Journal "WEST-EAST", Deputy Director of the International Scientific-Pedagogical Organization of Philologists "WEST-EAST" (Georgia).

e-mail: a.zoia777@gmail.com

Сведения об авторе: Зоя Адамия - Доктор филологии, проф., Институт русского языка и литературы Цхум-Абхазской академии наук. Главный редактор научного журнала «WEST-EAST». Заместитель директора международной научнопедагогической организации филологов «Запад-Восток» (Грузия).

e-mail: a.zoia777@.gmail.com

DOI:

\title{
ZOONYM WOLF IN PHRASEOLOGY AND PARAMIOLOGY: CULTURAL CONNOTATIONS (IN RUSSIAN, UKRAINIAN, CHECHEN AND ENGLISH)
}

\author{
Luiza N. Gishkaeva \\ PhD in Philology, Associate professor \\ RUDN University \\ (Moscow, Russia) \\ e-mail: adv88-02@mail.ru \\ Olga V. Lomakina \\ Doctor of Philological Sciences, \\ Professor, St. Tikhon's Orthodox University, \\ Peoples' Friendship University of Russia \\ (Moskow, Russia) \\ e-mail: rusoturisto07@mail.ru
}

The publication has been prepared with the support of the RUDN University Program 5-100

\begin{abstract}
The article is devoted to the description of connotations of a zoonym wolf in unrelated and related languages - in Russian, Ukrainian, Chechen and English. We study a zoonym (animalism) as a culture-specific component of phraseology and paramiology, which presents the universal and the national in the language and ads to the knowledge of a national world view of a specific nation. The article gives semantic peculiarities of phraseological units and paroemias, which include an animalism wolf: describing the ways of wolf and the features of the animal, its appearance and the description of the parts of its body, its habitat. It is proved in the article that even in different unrelated languages the lexical unit wolf has negative connotations. There are only few paroemias containing positive connotations of a zoonym wolf.
\end{abstract}

Key words: zoonyms, phraseological units, paroemia, value, zoonym wolf

\section{ЗООНИМ ВОЛК ВО ФРАЗЕОЛОГИИ И ПАРЕМИОЛОГИИ: КУЛЬТУРНЫЕ КОННОТАЦИИ (НА МАТЕРИАЛЕ РУССКОГО, УКРАИНСКОГО, ЧЕЧЕНСКОГО И АНГЛИЙСКОГО ЯЗЫКОВ)}

\author{
Луиза Нахидовна Гишкаева \\ Кандидат филологических наук, доцент \\ Российский университет дружбы народов \\ (Москва, Россия) \\ e-mail: adv88-02@mail.ru \\ Ольга Валентиновна Ломакина \\ Доктор филологических наук, профессор \\ Православный Свято-Тихоновский гуманитарный университет, \\ Российский университет дружбы народов \\ (Москва, Россия) \\ e-mail: rusoturisto07@mail.ru
}

Публикация подготовлена при поддержке Программы РУДН "5-100".

Аннотация. Статья посвящена описанию коннотаций зоонима волк в неродственных и родственных языках - русском, украинском, чеченском и английском. Зооним (анимализм) рассматривается нами как культурно маркированный компонент 
фразеологии и паремиологии, представляющий собой универсальное и национальное в языке, дополняющий сведения о национальной картине мира конкретного народа. В статье показаны семантические особенности фразеологических единиц и паремий, включающих анамализм волк: представлены повадки животного и свойственные ему признаки, внешний вид волка и его частей тела, среда обитания. В статье доказано, что в разных, даже неродственных языках, фразеолексема волк имеет отрицательные коннотации. Единичны русские паремии, включающие положительные коннотации зоонима волк.

Ключевье слова: зоонимы, фразеологическая единица, паремия, оценка, зооним волк / wolf / борз / вовк

ВВЕДЕНИЕ Как известно, межъязыковое сопоставление фразеологических единиц (ФЕ) и паремий позволяет выявить познавательный потенциал, представить богатство культурных коннотаций. «При этом важно учитывать, что разные группы фразеологии и паремиологии имеют различные качественные и количественные квоты познавательного потенциала» (Lomakina 2018: 103). Сравнение человека с представителями животного носит универсальный характер, «поскольку человек, наблюдая за окружающей его действительностью, устанавливает сходства и различия между собой и другими представителями животного мира» (Гишкаева 2017: 152), однако перечень анимализмов, участвующих в создании ФЕ и паремий, зависит от климатических и природных факторов, условий внешней среды. Кроме того, каждый народ имеет «свои специфические коннотации, вызванные животным или птицей» (Наyrullina 1996: 78). Изучение зоонимов (анимализмов) как культурно маркированных компонентов фразеологии и паремиологии представляет универсальное и национальное, дополняет сведения о национальной картине мира конкретного народа. Цель данной статьи представить коннотативные характеристики зоонима волк в паремиологии и фразеологии родственных неродственных языков - русского, украинского, чеченского и английского.

ОБЗОР ЛИТЕРАТУРЫ . Зоонимы, наряду с соматизмами, фитонимами, колоронимами, являются частотным и культурно маркированным компонентом ФЕ и паремий в разноструктурных языках (см., например: Gishkaeva 2012, 2017; Egorov 2011; Zol'nikova 2009; Isaev 2015; Lomakina, Mokienko 2018; Ruseckaya 2010, 2012). Изучению фразеологического компонента волк в сравнительно-сопоставительном аспекте посвящены работы В.М. Каменской (2007), С.В. Миронова (2013), Е.М. Черниковой, Н.В. Шатрович (2010), Л. Н. Гишкаевой, Ю. Н. Эбзеевой, В. В. Барабаша, А. Н. Широбокова (2017). Авторы планомерно доказывают, что фразеолексема волк является культурным феноменом в анализируемых языках, поскольку служит основой для образования фразеологических гнёзд, активно используется в различных текстах в роли прецедентной единицы. Изучение ФЕ и паремий определённой семантической группы позволяет выявить национальное и интернациональное в сопоставляемых языках и способствует эффективной межкультурной коммуникации.

МАТЕРИАЛЫ И МЕТОДЫ ИССЛЕДОВАНИЯ. ВЫбор методов исследования обусловлен задачами работы и спецификой анализируемого материала: сравнительно-сопоставительный, лингвокультурологический, аналитический, компонентного анализа. Материал исследования (более 500 единиц) был извлечён приёмом сплошной выборки из актуальных лексикографических источников (Кунин А.В. «Большой англо-русский фразеологический словарь», 2005; Глуховцева І. Я. «Словник модифікованих стійких сполучень слів в узусі кінця XX - початку XXI століття», 2013; Козлова Т.В. «Идеографический словарь русских фразеологизмов с названиями животных», 2001; Мокиенко В.М., Никитина Т.Г., Николаева Е.К. «Большой словарь русских пословиц», 2010; Байсултанов Д.Б. «Чеченско-русский фразеологический словарь» в 3-х томах, 2016; «Тезаурус русских идиом: семантические группы и контексты», 2018).

РЕЗУЛЬТАТЫ И ДИСКУССИЯ. Волк, лиса, медведь и заяц относятся к диким животным, обитателям лесов. Согласно наблюдениям В.М. Каменской, «фразеопродуктивность названий диких животных в среднем в несколько раз ниже, чем у домашних животных. В русской стержневой системе эта группа составляет $17 \%$, в испанской - 12,4 \%. < ..> В результате того, что стержневая система у названий диких животных невелика по объему, базовый стержневой компонент несет основную стержневую нагрузку и обладает высокой продуктивностью» (Kamenskaya 2007: 91).

С целью изучения инвариантного образа животного мира традиционно выделяют его координаты. Так, для царства животных важными являются следующие: а) животное и его части тела; б) животное и его потомство; в) животное и его повадки; г) животное и среда его обитания или содержания; д) животное и свойственные ему признаки; е) животное и приписываемые ему признаки (Kirillova 2017: 172).

Зооним волк обладает широчайшим спектром самых разных коннотаций, подчас не совпадающих в различных языках. Перед тем как рассмотреть ФЕ и паремии с обозначенным анамализом, представим общую информацию об этом животном.

Согласно А. Брэму, волк «похож на большую, длинноногую, худощавую собаку с хвостом, опущенным вниз, а не загнутым кверху. Отличительными признаками волка оказываются следующие: худощавое туловище, брюхо подтянуто, ноги тонкие, хвост покрыт длинной шерстью и висит до пяток. Морда кажется вытянутой и заострённой; широкий лоб спускается круто вниз, глаза расположены косо, уши всегда стоячие» (Brem 2004: 116).

Перечислим паремии, в которых отмечается внешний вид волка, его физические характеристики. Чеченская паремия отражает внешнее сходство собаки и волка: Къанъеллачу барзах пхьу хилла (Постаревший волк превратился в кобеля), употребляется, когда речь идёт о возрастных изменениях. В ряде русских пословиц, в том числе диалектных, подчёркивается антагонизм волка и собаки: Не боится волк собаки, да не любит её 
вяки, Не боится волк собаки, да не любит звяги (смоленская), рус. Не бойся, волк. Собаки, а бойся звяги (новгородская), звяги - собачий лай. Аналогичная пословица существует в чеченском языке: Чеченская пословица Барзах жlавла иа хила, амма борз эшаеш жlаьла хуьлу (Волк не стал псом, но пёс может стать волкодавом) имеет русский аналог Волк кормлёный, конь лечёный, жид крещёный да недруг замирённый равно надёжны, говорит о том, что волку нельзя доверять, надо всегда быть готовым к неожиданностям. В русской пословице Волка ноги кормят и украинской пословице Вовка ноги годують закреплена мысль о том, что получить результат может только тот, кто работает, а не сидит, что связано с необходимостью волка добывать пищу, чтобы прокормиться. Английская пословица The wolf may lose his teeth, but never his nature и её русский аналог Волк каждый год линяет, да обычай не меняет (Волк и всякий год линяет, а нрав переменяет) обращает внимание на регулярную смену шерсти у млекопитающих, что отражает семантику регулярности, повторяемости.

Паремиологический фонд запечатлевает не только внешний вид животного, но и его повадки, поведение. Эти сведения переосмысливаются и становятся характеристикой человека. Волк - хищное животное (рус. Волк, так волчью хватку и знает; рус. Ловит волк, поколе волка не поймают; рус. Волк глядит на хозяйскую заботу, а ташит овец и из счёта, и без счёту; рус. Волк хищник по природе, а человек по зависти; чечен. Барзо баьхьна ybcmazl, и1а ияа беъна - Овца, похищенная волком, домой не вернулась; англ. You have set the wolf to keep the sheep - Вы поставили волка следить за овцами), кровожаден (рус. Отведал волк конинки с хвоста, чечен. Барзой, вирой доттагlалла лелийна, барзо вир диъна - Дружили волк и осёл, волк и съел осла; рус. Пожалел волк кобылу - оставил хвост да гриву). Волк жестоко расправляется не только с домашними животными, но и с дикими зверями: чечен. Барзаца къовсаделлачу иххьогало ворта кагйина (Потягавшаяся с волком лисица шею себе свернула). Однако бывают звери и страшнее волка: чечен. Барзах ведда дитта тle ваьлла, ткъа дитта mlexb lam ча хила (Испугался волка и забрался на дерево, а там медведь сидит); рус. Бежал от волка, да попался медведю.

Паремиологический и фразеологический фонд запечатлевает и другие качества волка: недружелюбность (чечен. Бартболчу ициигаша бартбоиу берзалой эшийна - Дружные кошки недружных волков победили), скрытность (рус. скрытный как волк), изменить его могут лишь непримирые обстоятельства (рус. Смирен волк 8 капкане).

Мифологическая традиция разных народов связывает волка с тёмными силами и с миром мёртвых, что находит отражение в следующих паремиях: рус. Видел волк зиму, а чёрт схиму; Помянули волка, а он тут; Про волка речь, а он навстречь. Этим фактом можно объяснить трансформацию в украинском языке: Не такий страшний чорт, як його малюють - не такий страшний вовк, як озвірілий браконьєр, где вместо компонента чёрт в качестве субститута употребляется зооним вовк.

В языковом сознании многих народов образ волка ассоциируется с голодом, что находит отражение в русской фразеологии: волчий аппетит; волком смотреть на еду; голодный, как волк; прожорливыцй как волк, английской паремиологии: Hunger drives the wolf out of the woods (Чувство голода гонит волка из леса). Сравнение голодного человека с волком можно объяснить с биологической точки зрения: подобно тому, как меняется поведение у голодного волка (волк «забывает всякую осторожность и становится не только смелым, но и нахальным. Для голодного волка не существует опасности; он ничего не боится, и его ничем нельзя испугать» (Brem 2004: 118)), так меняется и поведение человека. Таков характер прототипической ситуации в русских пословица Сытый волк смирнее завистливого человека и Сытый волк смирнее ненасытного телёнка.

Средой обитания волка является лес, что содержится в следующих единицах: рус. Сколько волка ни корми, он всё в лес смотрит и аналога англ. No matter how well you feed a wolf he is constantly looking towards the wood, укр. Скільки вовка не годуй, а він [усе] в ліс дивиться. Семантика приведённых пословиц отражает поведение волка как дикого зверя, не поддающегося дрессировке. В пословицах рус. Волков бояться - в лес не ходить и укр. Вовків боятися - у ліс не ходити волк предстаёт зверем, образ которого гораздо страшнее, чем на самом деле, поэтому значение пословицы «если бояться трудностей или опасных последствий, не следует начинать какое-либо дело; чтобы добиться какого-либо результата, надо рисковать». Подобную семантику имеет и чеченская пословица Барзах кхийринчу 1уьнан жа ияа дебна (У пастуха, боявшегося волка, стадо не размножилось). Указание на лес содержится в русских пословицах, содержащих компоненты семантического поля «лес»: Бояться волка - бегать и от белки; Бояться волков - быть без грибков.

В фонде сопоставляемых языков почти нет ФЕ и пословиц, содержащих положительные коннотации рассматриваемого анимализма. Русские пословицы На волка поклёп, а зайцы кобылу съели; Не для волка растут красные яблоки отражают сочувственное отношение к волку, в них экстраполируется семантика, выраженная ФЕ вали на серого. Это перекликается с позицией св. Франциска Ассизского, воспринимавшего всех зверей как братьев: «Святой Франциск из Ассизи <...> радовался буквально всему на свете. Даже к диким зверям он обращался “брат заяц” или “брат волк”» (Billevich 2006: 277).

ЗАКЛЮЧЕНИЕ. Проведённое исследование показало, что зооним волк является распространённой фразеолексемой в русском, украинском, чеченском и английском языках. Анализ корпуса ФЕ и паремий с данным анимализмом показал, что в них представлены повадки животного и свойственные ему признаки, внешний вид волка и его частей тела, среда обитания. Семантика почти всех рассматриваемых единиц в родственных и неродственных языках содержит отрицательные характеристики волка, представленные в виде 
отрицательных культурно маркированных коннотаций. Единичны русские пословицы, включающие положительные коннотации зоонима волк.

\section{ЛЕКСИКОГРАФИЧЕСКИЕ ИСТОЧНИКИ}

Gluhovceva I. Ya. Slovnik modifikovanih stiykih spoluchen' sliv v uzusi kincya HH - pochatku HHI stolittya / vidpov. red. P. Yu. Gricenko; Derzh. zakl. «Lugan. nac. un-t imeni Tarasa Shevchenka». - Lugans'k: Vid-vo DZ «LNU imeni Tarasa Shevchenka», 2013. $-328 \mathrm{~s}$

Kozlova T.V. Ideograficheskiy slovar' russkih frazeologizmov s nazvaniyami zhivotnyh. - Moskva: Izdatel'stvo «Delo i servis», 2001. $-208 \mathrm{~s}$.

Kunin A.V. Bol'shoy anglo-russkiy frazeologicheskiy slovar'. Moskva: Drofa. 2005. 1214 s.

Mokienko V.M., Nikitina T.G., Nikolaeva E.K. Bol'shoy slovar' russkih poslovic. Moskva: ZAO «OLMA Media Grupp», 2010. $1024 \mathrm{~s}$.

Tezaurus russkih idiom: semanticheskie gruppy i konteksty / Baranov A.N., Voznesenskaya M.M., Dobrovol'skiy D.O. Kiseleva K.L., Kozerenko A.D. / pod red. A.N. Baranova i D.O. Dobrovol'skogo. 2-e izd., ispr. i dop. Moskva: OOO «LEKSRUS», 2018.888 s.

Chechensko-russkiy frazeologicheskiy slovar': okolo 12 tys. frazeologicheskih edinic chechenskogo yazyka: v treh tomah / Baysultanov D. B. - Izd. 2-e, dop., pererab. - Groznyy: Groznenskiy rabochiy, 2016. T. 1: A - D. - 2016. - 732 s.; T. 2: E - S. - 2016. 590 s.; T. 3: T - I. - 2016. - 509 s.

\section{LIST OF REFERENCES}

Billevich, V. (2006). Shkola ostroumiya ili kak nauchit'sya shutit' [The school of smartness or how to learn to joke?]. Moskva-SanktPeterburg, Kiev: Izdatel'skii dom «Vil'yamS», 336.

Brehm, A. (2004). Zhizn' zhivotnykh [Animals' life]. Moskva: EHKSMO, 960.

Gishkaeva, L.N. (2012). Frazeologizmy s komponentom-zoonimom i fitonimom v sovremennom pireneiskom $i$ meksikanskom natsional'nykh variantakh ispanskogo yazyka [Phraseological units with a component zoonym and a phytonym in modern Iberian and Mexican national variants of Spanish] Avtoref. diss...kand.filol.nauk. Moskva, 18.

Gishkaeva, L.N., Ebzeeva, Yu.N., Dubinina N.V., Barabash V.V., Shirobokov A.N. (2017). Kul'turnye konnotatsii russkogo zoonima «volk» i ego ekvivalentov v angliiskom, ispanskom i chechenskom yazykakh [Cultural connotations of a Russian zoonym «wolf» and its equivalents in English, Spanish and Chechen] // Sibirskii filologicheskii zhurnal. № 3., 151-160. DOI: 10.17223/18137083/60/13

Egorov, A.V. (2011). Udmurtskaya somaticheskaya frazeologiya ( $v$ sopostavlenii s vengerskoi) [Udmurt somatic phraseology (in comparison with the Hungarian)]. Ekaterinburg: Ural'skoe otdelenie Rossiiskoi akademii nauk.

Zol'nikova, Yu. V. (2009). Tsvetooboznacheniya vo frazeologicheskoi kartine mira nemetskogo i russkogo yazykov [colour naming in phraseological world view of German and Russian]// Vestnik Chelyabinskogo gosudarstvennogo universitetA. 2009. № 30 (168). Filologiya. IskusstvovedeniE. VyP. 35, 88-93.

Isaev, Yu.N. (2015). Fitonimicheskaya kartina mira v raznostrukturnykh yazykakh: Avtoreferat diss.....doktorafilol.nauk [Phytonymical world view in multistructural languages]. CheboksarY, 43.

Kamenskaya, V. M. (2007). Osobennosti sterzhnevykh komponentov zoomorfnykh frazeologizmov v ispanskom i russkom yazykakh [The peculiarities of a core component of zoomorphic phraseological units in Spanish and Russian] // Vestnik Voronezhskogo gosudarstvennogo universiteta. Seriya: Lingvistika i mezhkul'turnaya kommunikatsiya. № 2(2), 89-92.

Lomakina, O.V., Mokienko, V.M. (2018). Karpatorusinskie somaticheskie paremii na slavyanskom fone [Karpatorusinskie somatic paroemias related to Slavic] // Slavyanskaya mikrofilologiya / pod redaktsiei Aleksandra D. Dulichenko, Motoki Nomati. Sapporo : Slavic-Eurasian Research Center, Hokkaido University, (Slavic Eurasian studies ; no. 34), 103-128.

Mironova, S. V. (2013). Stereotipnyi obraz volka v russkom i tatarskom yazykovom soznanii [Stereotyped image of a wolf in Russian and Tatar linguistic consciousness] // Vestnik Chelyabinskogo gosudarstvennogo universiteta, № 4 (295), 70-78.

Rusetskaya, I.Ya. (2010). Frazeologicheskie somatizmy russkogo i litovskogo yazykov [Phraseological somatisms in Russian and Lithuanian]. // Mir russkogo slova, № 3, 27-30.

Rusetskaya, I.Ya. (2012). Kontseptualizatsiya kul'turnykh stereotipov dusha i telo v russkoi somaticheskoi frazeologii (s privlecheniem litovskikh parallelei) [Conceptualisation of cultural stereotypes soul and body in Russian somatic phraseology]. Avtoreferat kand. diss. ... filol. nauk. Moskva, 24.

Khairullina, R.Kh. (1996). Kartina mira v russkoi frazeologii [World view in Russian phraseology]. Moskva: Prometei, 147.

Chernikova, E.M., Shatrovich N.V. (2010). Zoonimy i ornitonimy v sostave frazeologizmov kak sposob otrazheniya lingvokul'turnoi informatsii (na materiale frantsuzskogo i ital'yanskogo gazetnogo teksta) [Zoomyms and ornithonyms in phraseological units as a way of reflecting linguistic and cultural information (in French and Italian newspapers)]. // Vestnik Yuzhno-Ural'skogo gosudarstvennogo universiteta. № 21, 46-50.

Ehctes, Pinkola K. (2007). Begushchaya s volkami. Zhenskii arkhetip v mifakh i skazaniyakh. Perevod s angl. [Running with the wolves. Woman's archetype in myths and legends]. Moskva: OOO Izd-vo «Sofiya», 496.

\section{For citation:}

Gishkaeva, L.N. \&. Lomakina, O.V. (2019) ZOONYM WOLF IN PHRASEOLOGY AND PARAMIOLOGY: CULTURAL CONNOTATIONS (IN RUSSIAN, UKRAINIAN, CHECHEN AND ENGLISH) International Scientific-Pedagogical Organization of Philologists “WEST-EAST” (ISPOP). Scientific Journal WEST-EAST. Vol 1/1 N1 (October, 2019). p.p. 23-27. doi:

\section{Для цитирования:}

Гишкаева, Л.Н., Ломакина, О.В. (2019) ЗООНИМ ВОЛК ВО ФРАЗЕОЛОГИИ И ПАРЕМИОЛОГИИ: КУЛЬТУРНЫЕ КОННОТАЦИИ (НА МАТЕРИАЛЕ РУССКОГО, УКРАИНСКОГО, ЧЕЧЕНСКОГО И АНГЛИЙСКОГО ЯЗЫКОВ). // 
International Scientific-Pedagogical Organization of Philologists "WEST-EAST" (ISPOP). Scientific Journal WEST-EAST. Vol 1/1 N1 (October, 2019). C. 23-27. doi:

Information about the author: Luiza N. Gishkaeva- PhD, Associate Professor of Department of Foreign Languages of the Philological Faculty of RUDN University;

Research interests: semantics, phraseology, cultural linguistics, intercultural communication, textology

e-mail: adv88-02@mail.ru

Сведения об авторе: Гишкаева Луиза Нахидовна - кандидат филологических наук, доцент, Российский университет дружбы народов

e-mail: $\underline{\operatorname{adv} 88-02 @ \text { mail.ru }}$

Information about the author: Olga V. Lomakina - Doctor of Philological Sciences, professor of the Department of Foreign Languages, Faculty of Philology, the Peoples' Friendship University of Russia, Professor of the Department of Modern Russian Language at St. Tikhon's Orthodox Humanitarian University (Russia). e-mail: rusoturisto07@mail.ru

Сведения об авторе: Ольга Валентиновна Ломакина - доктор филологических наук, профессор, Российский университет дружбы народов, Православный Свято-Тихоновский гуманитарный университет (Россия) e-mail: rusoturisto07@mail.ru

DOI:

\title{
COMPARATIVE RESEARCH OF TURKISH LANGUAGES (KAZAKH, TURKISH AND UZBEK) IN THE HISTORICAL ASPECT
}

\author{
Aigul Baituova \\ Ph.D, Associate Professor \\ Khoja Akhmet Yassawi International Kazakh-Turkish Univesity, Turkestan, Kazakhstan \\ (Turkestan, Kazakhstan) \\ e-mail: baituaigul@mail.ru
}

\begin{abstract}
A detailed study of the complex issue of differentiation and integration of Turkic languages, both in general Turkic and regional plans, is of great interest for Turkic studies. Naturally, when studying the structure of a language, each researcher had his own approach to their study and interpretation. This sometimes makes it difficult to compare studies of different authors, sometimes studies are contradictory. In Turkology, there are still no developed scientific methods for comparative study of large representatives of different genetically independent groups in this case - Kypchak, Oguz and Karluk - which are Kazakh, Turkish and Uzbek languages. In a number of comparative studies existing in Turkology, including in the studies of the phonetic structure of groups of closely related Turkic languages, a scientifically developed unified methodological approach is not always present. Information previously obtained by different authors of research results for different purposes can be characterized as general, inconsistent, fragmentary, which do not represent especially composed essays, built according to a specific plan. The purpose of this characteristic with a brief insight into the processes of the studied languages formation is an attempt to link the current state of the language with their historical process of formation and ongoing development. Historical, ethnic, social, demographic, cultural, administrative, territorial-geographical and other objective factors are undoubtedly decisive, leaving their definite imprints in the language development of the ethnic group. At the same time, deviations in the structure of the studied languages from the Pra-Turkic state find a well-known explanation also in extraordinary situations of history.
\end{abstract}

Keywords: research, comparative, Turkology, formation

\section{СРАВНИТЕЛЬНО-СОПОСТАВИТЕЛЬНОЕ ИССЛЕДОВАНИЕ ТЮРКСКИХ ЯЗЫКОВ (КАЗАХСКОГО, ТУРЕЦКОГО И УЗБЕКСКОГО) В ИСТОРИЧЕСКОМ АСПЕКТЕ}

\author{
Айгуль Байтуова \\ к.ф.н., доцент \\ Международный казахско-турецкий университет им. Х.А Ясави, \\ (Туркестан, Казахстан) \\ e-mail: baituaigul@mail.ru
}

\begin{abstract}
Аннотация. Для тюркологии представляет большой интерес детальное исследование сложного вопроса дифференциации и интеграции тюркских языков как в общетюркском, так и в региональном планах. Естественно, каждый исследователь при изучении структуры того или иного языка имел свой собственный подход к их изучению и интерпретации. Это порой затрудняет сравнение исследований разных авторов, иногда исследования оказываются противоречивыми. Выработанных
\end{abstract}

